\title{
Women's Satisfaction with Antenatal Care in Accredited and Non Accredited Family Health Units
}

\author{
Mona Ahmed Sayed ${ }^{1}$ Manal Farouk Moustafa ${ }^{2}$ \& Entisar Mohamed Youness ${ }^{3}$ \\ 1- Detective Nursing Ashmoon Health District Monufya, Egypt. \\ 2- Professor of Obstetrics and Gynecological Nursing, Faculty of Nursing, Assiut University Egypt. \\ 3- Assistant professor of Obstetrics and Gynecological Nursing Faculty of Nursing, Assiut University, Egypt.
}

\begin{abstract}
The Aim of the study, was: to assess women's satisfaction about antenatal care between accredited and non accredited family health units. And Assess the standards of antenatal care provided through accredited and non accredited family units. Research design: was a descriptive -cross sectional study research design .setting: This descriptive study was conducted in family health units which affiliates to 4 settings in Ashmoon Mounfya Sample: consisted of 500 pregnant women .Results of this study presented that $84.4 \%$ of the studied women were satisfied among accredited family health units versus 17.2 only among non accredited family health units, also $77.2 \%$ of health care providers were reasonably met of quality indicators checklist in the accredited family health units versus $38.8 \%$ in the non accredited family health units with a highly statistical significant differences. Conclusion: women were more satisfied among accredited family health units than in non accredited family health units. Recommendation: Based on the finding of the current study . Ministry of health and population should give more attention to primary health care units accreditation program to be implemented in all primary health care units.
\end{abstract}

\section{Key words: Satisfaction, Antenatal care, Accredited \& Non Accredited Family Health Units, Quality.}

\section{Introduction}

Egypt health system consists of a wide range of public and private health care services which allows good geographic accessibility. Various facilities provide different types of services covering; primary health care, secondary and tertiary care. Primary Health Care (PHC) includes services like; family planning, maternal care, child care, dental care, health educational services, communicable diseases control, emergency care (first aid services) and environmental health services. Primary Health care is provided by Public Primary Health Care centers all over Egypt (Abdel-Razik et al., 2012).

The 5 th millennium development goal (MDG) aims at reducing maternal mortality by $75 \%$ by the year 2015. According to the World Health Organization (WHO), there was an estimated 358,000 maternal deaths globally in 2008. Developing countries accounted for $99 \%$ of these deaths of which threefifths occurred in Sub-Saharan Africa. (Bhutta, et al., 2010) (WHO,2010).

Maternal mortality remains a major public-health issue in developing countries. According to the WHO, 536,000 women die every year in the world from causes relating to pregnancy, childbirth, or postpartum. The majority of maternal deaths avoided if women had access to quality medical care during pregnancy (Van et al., 2010).

According to Egypt demography and health survey, slightly more than one quarter of Egyptian pregnant women do not receive antenatal care. However, among those who receive antenatal care only onethird of them received advised about signs of

obstetric complications and where and when to seek medical assistance (El-Zanaty \& Way, 2009). In Egypt, maternal mortality ratio has declined dramatically from $174 / 100,000$ live births in 19921993 to $67.6 / 100,000$ live births in 2005, a further decline to $44.6 / 100,000$ was also reported by 2009 (GHC, 2010, WHO, 2010).

Pregnancy is one of the most important periods in the life of a woman, her family and the society. Therefore extraordinary attention is given to antenatal care. In recent years, emphasis on improving the quality of care provided by the nation's health setting has increased significantly (Fikry et al., 2015).

Antenatal care is regarded as a cornerstone of maternal health care and better evidence about what works and what does not work to reduce maternal mortality exists. Many elements of antenatal care have no impact in reducing complications and maternal deaths, so the WHO guidelines are specific as regards the timing and content of antenatal care visits according to gestational age and the guidelines insist that "only examinations and tests that have been proven to be beneficial should be performed"

(EL Gammal, 2014).

Quality improvement efforts in developing countries could focus on strengthening the process of care. Special attention is needed to improve interpersonal behavior, as evidence from the review points to the importance women attach to being treated 
respectfully, irrespective of socio-cultural or economic context. Further research on maternal satisfaction is required on home deliveries and relative strength of various determinants in influencing maternal satisfaction (Abdel Latif, 2013) Accreditation of primary health care units has been part of the health sector reform in Egypt adopting the family health care approach model .Evaluation of such efforts at the level of delivered health services will add insight on the progress and value of accreditation (Al Tehewy et al., 2009). Accreditation is an essential part of quality system related to healthcare in more than 70 countries .Accreditation of healthcare organizations is optional and voluntary in some countries, while in other countries accreditation is mandated by government (pomey, et al., 2010).

Worldwide, accreditation has proven to have many benefits. Patients are the biggest beneficiary with high quality of care and patient safety. It raises community confidence in the services provided by the health care organization and affords the opportunity to the health care unit to benchmark with the best. Additionally, accreditation provides access to reliable and certified information on facilities, infrastructure and level of care. The benefits of accreditation also include providing a framework to help create and implement systems and processes that improve operational effectiveness (National accreditation Board, 2012).

The criteria for selecting the dimensions are based on their relative importance in defining quality of services in Egypt. Eight categories were selected as the most important items to be measured in the accreditation, including Patient Rights, Patient Care, Safety, Management of the facility, Management of Support Services, Management of Information System, Quality Improvement Program and Family Practice (Zenhom et al., 2014).

Satisfaction with antenatal care services motivate pregnant women to seek and continue antenatal care whereas dissatisfaction with antenatal care services results in decreased utilization. It is well known that most deaths can be prevented if adequate and timely obstetric care is provided but if nothing is being done to avert maternal deaths (Dahahi, et al., 2015).

The result of patient satisfaction surveys can be used to monitor the quality of indicators of health care provided to find out any shortages, to provide the necessary interventions and as a valuable source of strategic planning of health services (Al Qahtani et al., 2012).

Measurement of patient satisfaction plays an important role in raising accountability among health care providers. It is an indicator of the quality of health care equation. Although system aspects such as cost, access, availability and waiting time related to patient satisfaction, they have been less important than the human aspect of medical care (APP,2009) .

\section{Significance of the study}

Every minute of every day, some where in the world , a women dies as a result of pregnancy and delivery. Many causes of maternal mortality and morbidity are avoidable with effective obstetric interventions and proper antenatal care (Rogan \& wind 2010).

The estimated Maternal Mortality Ratio (MMR) in Sudan is 1107 per 100.000 live births and represents one of the highest in WHO-EMRO region

(UND,2010 )In spite of increasing importance of quality of antenatal car worldwide, accurate information about the quality or efficiency of antenatal care practices and clients satisfaction with such care are less often available or investigated in many countries where they are most needed the main goal of $\mathrm{MOH}$ (Ministry Of Health) andthe central role of primary care centers, little is known about the satisfaction of women with the quality of care provided by primary health care centers (Habib et al; 2009 ).

Accreditation may have an important role in improving quality of care. From this point the researcher conduct this study to evaluate Women's satisfaction of Antenatal care between Accredit and not accredited Family Health Units At Ashmoon Monufya .

\section{Aim of the study}

This Study Aims to

- Assess the quality of antenatal care provided through accredited and not accredited family health.

- Assess women's satisfaction about antenatal care between accredited and not accredited family health.

\section{Subjects \& methods \\ Research Design}

Descriptive -Cross sectional study design was utilized in carrying out this study .

\section{Setting}

The study was conducted at four family health units two accredited family health units (Manyle Doweeb and Mahalt Sobk) and two non accredited family health units (ElGhonamya and Sheashaa) Ashmoon Mounofiya.

\section{Sample}

According to sample size equation the sample was included 500 pregnant women which included in this study.

$$
\mathrm{Ss}=\mathrm{Z}^{2} *(\mathrm{p}) *(1-\mathrm{p})
$$

$$
\mathrm{C}^{2}
$$


$\mathrm{Z}=\mathrm{Z}$ value (e.g. 1.96 for $95 \%$ confidence level )

$\mathrm{P}=$ Percentage pinking a choice, expressed as decimal $\mathrm{C}=$ confidence interval , expressed as decimal (e.g., $.04= \pm 4$ )

\section{Subjects}

All pregnant women included in the study were randomly assigned into two groups ,250 women for each group, group one was the women from accredited family health units and group two was the women from non accredited family health units .Randomization was done by using computer generated tables in closed envelop.

\section{Sample characteristics}

The sample was chosen according to the following criteria.

\section{Inclusion criteria}

All pregnant woman who attending Manyle Doeeb and Mahalt Sobk, ElGhonamya and Sheashaa family health units.

\section{Exclusion Criteria}

High risk pregnancies : diabetes,hypertention and preclampsia, Emergency cases and Woman refuse participant of the study.

Tools of the study

Tools of this study was divided into three parts

First part

- Structured Interviewing Questionnaire developed by the investigator which included the following data

Socio-Demographic data (e.g.,age , occupation, \& level of education.

Obstetrical history which included

Past obstetric history about reproductive parameters as : Number of parity, Number of gravidity, Number of still births ,Number of abortions, Number of neonatal deaths before 7 days and Number of living children .

previous pregnancy data as, either it was normal or complicated such as hypertensive disorders of pregnancy, diabetes mellitus, premature rupture of membranes (PROM), anemia, oligohyrominos, placental abruption, placenta previa and others

previous labour data, either it was normal or complicated by preterm birth , post term ,stillbirth , neonatal death ,macrosomia ,low birth weight and others ,Mode of the previous delivery either it was spontaneous vaginal delivery (SVD) ,operative vaginal delivery (OVD) and instrumental (forceps or ventous) or cesarean section (C.S).

past medical history: Medical disorders such as : hypertension , diabetes mellitus, renal disease, heart disease, drugs specially in early pregnancy and history of previous operations .

\section{Second part}

To assess Women's Satisfaction Questionnaire tool
This part was designed by the investigator which included the following data : questions to assess the satisfaction about different aspects of quality of care as :-Location of the unit, accessibility, waiting time at Maternal and child Health $(\mathrm{MCH})$ room and outpatient clinic, waiting for investigation results, Cleanness of the unit, toilet and $\mathrm{MCH}$ room, Performance of physician like: examination time , communication manner, answering questions ,history taking ,explanation of the problem, Trusting the doctor, explaining causes of investigations and its results ,Privacy keeping ,Performance of the nurse ,trusting the nurse, answering questions, explanation of antenatal care advantages .

Family file and registration, presence of follow up card, accessibility to find the file and opinion about registration employee, comprehensive medical examination every visit, fetal heart sound, fetal movement ,fetal position and ultrasound (sonar ) if needed .

Performing health education program if she educated about good nutrition, Iron supplementation, discuss with women antenatal care advantages, physical activities during pregnancy, personal hygiene, teeth care, breast care, clothing, allowable medication during pregnancy, labor signs and alarming signs during labour .

The scoring system of satisfaction

The total score level was summed based on five points Likert scale was used to assess women satisfaction measured by using five points

- Very satisfied took (5) marks. satisfied took (4) mark.

- To some extent took (3) marks. Dissatisfied took (2) marks.

- Strongly dissatisfied took (1) marks.

- $75 \%$ to $100 \%$ was considered very satisfied.

- From $50 \%$ to less than $75 \%$ was considered satisfied.

- $25 \%$ to less than $50 \%$ was considered Dissatisfaction .

- Less than $25 \%$ was considered strongly dissatisfaction

\section{Third part}

III - Observation of quality indicators check list (Model of ministry of health and population standards MOHP)

The researcher of the current study designed the data collection tool based on Ministry of Health and Population for accreditation of family Health Units and Centers (2008) after its updating that approved by National Commission for Accreditation of Primary Health Care Facilities.

It consisted of observation of the antenatal care for the pregnant women and included: 
Full history and physical examination according to clinical guidelines ( personal history ,menstrual history , last menstrual history (LNMP) ,expected date of delivery (EDD), obstetric history (past history of difficult deliveries, symptoms of pre Eclampsia), family history ,past medical and surgical history -Immunization status (tetanus toxoid ).

Physical examination which include General Examination (weight, height ,blood pressure,edema of lower limbs, heart and chest examination, breast examination and thyroid examination).and Local Examination or Abdominal Examination ( fundal level , fundal grip , umbilical grip , first and second pelvic grip , auscultation of the fetal heart sounds \& palpation ). Referral of risk pregnancies to a specialist, according to clinical guidelines. The physician explained to all patients the diagnosis and treatment and any follow - up steps The physician using clear and simple language. The physician ensure that patients understood the message through feedback.

Educational messages on first visit (i.e nutrition, immunization status, importance of regular visit during pregnancy, breast feeding, use of drugs and medications during pregnancy, mode of delivery or delivery process.

A comprehensive history and physical and physical examination:- History (fetal movement, ask about new complaints and assess previous complaints).Diagnostic procedure (urine examination, blood analysis $\mathrm{Hb}$ and ultrasound referred ).

Physician is courteous to the women ( use clear and simple language, periodically checks if patient understands instructions and ask her if she have any questions).

Educate the pregnant woman about alarming sings such as bleeding, reassures patient about pregnancy and any special conditions and referral to educational sessions.

\section{Procedure}

This study carried out in 3 phases

\section{Preparatory Phase}

A review of current,past, local and international (global ) related literature in the various aspects of the problem using books, articles ,periodical magazines and websites were done and this ended by the Pilot study.

\section{Pilot study}

After preparation of the questionnaire it has been tested on $10 \%$ of cases (50) pregnant women (25 from accredited family health units and 25 from not accredited family health units ) to see the clarity of questions of the study tools and the proper needed modification was done. The pilot sample excluded from the study sample.

\section{Actual study Phase :- ( Procedure )}

An official permission was obtained from the Dean of the faculty of Nursing to the Manager of Ashmoon Health District Mounfya. The investigator collect the sample through four days every week one day weekly in each unit, The data was collected during Saturday and Tuesday, from the accredited family health units and during Sunday and Wednesdays from non accredited family health units according to maternal and child health schedule. The investigator went to the units at 9.00Am , introduce her self to all pregnant women who agreed to participate in the study through interviewing women (face to face interview ) and explaining the aim of the study.

\section{Before entering the Examination room}

After the investigator explained the purpose of the study to the pregnant women take an oral consent and ensuring that there was no risk or cost in participation the investigator interviewed each woman separately, obtained the socio demographic data ( name, age, residence, education ), Obstetrical and Medical history ( gravidity ,parity, still births , neonatal deaths, number of living children ).Data related to current pregnancy . and complete the data related to satisfaction items about different aspects of quality of care as

- Location of the unit, accessibility, waiting time at Maternal and child Health room and outpatient clinic .

- Cleanness of the unit,toilet and MCH room.

- Performance of physician like: examination time ,communication manner .

- Performance of the nurse, trusting the nurse , answering questions, explanation antenatal care advantages .

- Family file and registration, presence of follow up card, accessibility to find the file and opinion about registration employee., comprehensive medical examination every visit, and ultrasound (sonar ) if needed .

- Health education program if she educated about good nutrition, Iron supplementation .

- Antenatal care advantages, physical activities during pregnancy, personal hygiene, teeth care, breast care, clothing, allowable medication during pregnancy.

- labor signs and alarming signs during labour .

- Every woman were assessed between 30-40 minutes to obtained the necessary data .

\section{At Examination Room}

The investigator observe health care providers after agreement of the women according to accreditation tools ( standard modification from (MOHP , 2008 ) it is include observation of the antenatal care for the 
pregnant women and included : Full history and physical examination according to clinical guidelines ( personal history ,menstrual history, last menstrual history (LNMP) ,expected date of delivery (EDD), obstetric history (past history of difficult deliveries, symptoms of pre -Eclampsia ), family history, past medical and surgical history - Immunization status (tetanus toxoid) - Physical examination which include General Examination (weight, height ,blood pressure ,edema of lower limbs , heart and chest examination ,breast examination and thyroid examination).and Local Examination ( fundal level, fundal grip , umbilical grip , first and second pelvic grip, auscultation of the fetal heart sounds \& palpation) Referral of risk pregnancies to a specialist, according to clinical guidelines. The physician explains to all patients the diagnosis and treatment and any follow - up steps using clear and simple language. The physician ensure that patients understood the message through feedback.

Educational messages on first visit (i.e nutrition, immunization status, importance of regular visit during pregnancy, breast feeding, use of drugs and medications during pregnancy, mode of delivery or delivery process .

A comprehensive history and physical and physical examination
History ( fetal movement, ask about new complaints and assess previous complaints).

Diagnostic procedure ( urine examination , blood analysis $\mathrm{Hb}$ and ultrasound referred ).

Physician is courteous to the patient ( use clear and simple language, periodically checks if patient understands instructions and ask her if have any questions ).

Educate the pregnant woman about alarming sings such as bleeding, reassures patient about pregnancy and any special conditions and referral to educational sessions.

\section{Ethical consideration}

The study was approved by the ethical committees of the faculty of Nursing .Assiut University. No harmful procedure was affected the condition of pregnant women. Oral informed consent was taken from every woman before inclusion in the study

\section{Analysis / statistical design}

Data entry and statistical analysis were done by using Statistical Package for the Social Sciences ( SPSS version 20 ) under windows were applied descriptive statistics (i.e. frequency, percentage, mean and standard deviation) and tests of significant when P.value less than 0.05 and highly significant when P.value was less or equal 0.01 and was demonstrated in the form of graphs, figures and tables .

\section{Results}

Table (1): Distribution of the studied women attended to accredited and non accredited family health units according to their personal demographic characteristics.

\begin{tabular}{|c|c|c|c|c|c|}
\hline \multirow[t]{2}{*}{ Item } & \multicolumn{2}{|c|}{ Accredited (n=250) } & \multicolumn{2}{|c|}{ Non Accredited $(n=250)$} & \multirow[t]{2}{*}{ P. value } \\
\hline & No & $\%$ & No. & $\%$ & \\
\hline Age, mean \pm SD & \multicolumn{2}{|c|}{$24.24 \pm 4.2$} & \multicolumn{2}{|c|}{$24.44 \pm 4.17$} & 0.586 \\
\hline \multicolumn{6}{|l|}{ Level of Education } \\
\hline Illiterate & 7 & 2.8 & 5 & 2.0 & \multirow{4}{*}{0.217} \\
\hline Primary & 11 & 4.4 & 8 & 3.2 & \\
\hline Secondary & 158 & 63.2 & 180 & 72.0 & \\
\hline University & 74 & 29.6 & 57 & 22.8 & \\
\hline \multicolumn{6}{|l|}{ Occupation } \\
\hline Employed & 23 & 9.2 & 15 & 6.0 & \multirow{2}{*}{0.177} \\
\hline Housewife & 227 & 90.8 & 235 & 94.0 & \\
\hline \multicolumn{6}{|l|}{ Residence } \\
\hline Rural & 250 & 100.0 & 250 & 100.0 & \multirow{2}{*}{-} \\
\hline Urban & 0 & 0.0 & 0 & 0.0 & \\
\hline
\end{tabular}


Table (2): Distribution of the studied women attendance to accredited and non accredited family health units according to their obstetric history.

\begin{tabular}{|c|c|c|c|}
\hline \multirow[t]{2}{*}{ Item } & Accredited (n=250) & $\begin{array}{c}\text { Non Accredited } \\
(\mathbf{n}=\mathbf{2 5 0})\end{array}$ & \multirow[t]{2}{*}{ P. value } \\
\hline & Mean \pm SD & Mean \pm SD & \\
\hline Gravidity & $1.42 \pm 1.27$ & $1.34 \pm 1.08$ & 0.447 \\
\hline Number of Living children & $1.75 \pm 0.82$ & $1.72 \pm 0.78$ & 0.795 \\
\hline Number of dead children & $1 \pm 0$ & $0.04 \pm 0.2$ & $<0.001 * *$ \\
\hline Abortion & $0.41 \pm 0.64$ & $1.52 \pm 0.96$ & $<0.001 * *$ \\
\hline $\begin{array}{l}\text { Number of weeks in present } \\
\text { pregnancy }\end{array}$ & $28.71 \pm 5.46$ & $26.72 \pm 5.04$ & $<0.001 * *$ \\
\hline \multicolumn{4}{|l|}{ Number of visits, $\operatorname{No}(\%)$} \\
\hline First visit & $92(36.8 \%)$ & $159(63.6 \%)$ & \multirow{2}{*}{$<0.001 * *$} \\
\hline Repeated visit & $158(63.2 \%)$ & $91(36.4 \%)$ & \\
\hline
\end{tabular}

Table (3): Frequency distribution of the studied women toward their level of satisfaction in accredited and non accredited family health units.

\begin{tabular}{|l|c|c|c|c|c|}
\hline \multirow{2}{*}{\multicolumn{1}{c|}{ Satisfaction }} & \multicolumn{2}{c|}{ Accredited } & \multicolumn{2}{c|}{ Non Accredited } & \multirow{2}{*}{ P. value } \\
\cline { 2 - 5 } & No. & \% & No. & \% & \\
\hline Satisfied & 211 & 84.4 & 43 & 17.2 & \multirow{2}{*}{$<0.001^{* *}$} \\
\hline Unsatisfied & 39 & 15.6 & 207 & 82.8 & \\
\hline
\end{tabular}

** Statistically significant difference $(p<0.01)$

Table (4): Frequency distribution of observational checklist for health care providers (physician \&nurse) in accredited and non accredited family health units.

\begin{tabular}{|l|c|c|c|c|c|}
\hline \multirow{2}{*}{ Observational checklist } & \multicolumn{2}{|c|}{ Accredited } & \multicolumn{2}{c|}{ Non Accredited } & \multirow{2}{*}{ P. value } \\
\cline { 2 - 5 } & No. & \% & No. & \% & \\
\hline Not met & 5 & 2.0 & 14 & 5.6 & $<0.001 * *$ \\
\hline Poorly met & 23 & 9.2 & 136 & 54.4 & 38.8 \\
\hline Reasonably met & 193 & 77.2 & 97 & 1.2 & \\
\hline Fully met & 29 & 11.6 & 3 & & \\
\hline
\end{tabular}

$* *$ Statistically significant difference $(p<0.01)$ 
Table (5): Distrbution of the studied women according to their level of satisfaction toward location and accessibility among Accredited and non Accredited family health units .

\begin{tabular}{|c|c|c|c|c|c|}
\hline \multirow{3}{*}{ Item } & \multicolumn{4}{|c|}{ Location \& accessibility } & \multirow{3}{*}{ P. value } \\
\hline & \multicolumn{2}{|c|}{ Accredited } & \multicolumn{2}{|c|}{ Non Accredited } & \\
\hline & No. & $\%$ & No. & $\%$ & \\
\hline \multicolumn{6}{|c|}{ Location of the family health unit } \\
\hline Strongly Dissatisfied & 1 & 0.4 & 84 & 33.6 & \multirow{5}{*}{$<0.001 * *$} \\
\hline Dissatisfied & 96 & 38.4 & 56 & 22.4 & \\
\hline To some extent & 15 & 6.0 & 70 & 28.0 & \\
\hline Satisfied & 69 & 27.6 & 30 & 12.0 & \\
\hline Very satisfied & 69 & 27.6 & 10 & 4.0 & \\
\hline \multicolumn{6}{|l|}{ Access to the unit } \\
\hline Strongly Dissatisfied & 0 & 0.0 & 76 & 30.4 & \multirow{5}{*}{$<0.001 * *$} \\
\hline Dissatisfied & 11 & 4.4 & 62 & 24.8 & \\
\hline To some extent & 111 & 44.4 & 73 & 29.2 & \\
\hline Satisfied & 121 & 48.4 & 28 & 11.2 & \\
\hline Very satisfied & 7 & 2.8 & 11 & 4.4 & \\
\hline \multicolumn{6}{|c|}{ Waiting time for MCH room } \\
\hline Strongly Dissatisfied & 0 & 0.0 & 30 & 12.0 & \multirow{5}{*}{$<0.001 * *$} \\
\hline Dissatisfied & 1 & 0.4 & 89 & 35.6 & \\
\hline To some extent & 15 & 6.0 & 99 & 39.6 & \\
\hline Satisfied & 123 & 49.2 & 28 & 11.2 & \\
\hline Very satisfied & 111 & 44.4 & 4 & 1.6 & \\
\hline \multicolumn{6}{|c|}{ Waiting time for out patient clinic } \\
\hline Strongly Dissatisfied & 0 & 0.0 & 31 & 12.4 & \multirow{5}{*}{$<0.001 * *$} \\
\hline Dissatisfied & 0 & 0.0 & 82 & 32.8 & \\
\hline To some extent & 8 & 3.2 & 98 & 39.2 & \\
\hline Satisfied & 239 & 95.6 & 35 & 14.0 & \\
\hline Very satisfied & 3 & 1.2 & 4 & 1.6 & \\
\hline \multicolumn{6}{|c|}{ Waiting time for results of laboratory investigation } \\
\hline Strongly Dissatisfied & 0 & 0.0 & 40 & 16.0 & \multirow{5}{*}{$<0.001 * *$} \\
\hline Dissatisfied & 0 & 0.0 & 68 & 27.2 & \\
\hline To some extent & 14 & 5.6 & 80 & 32.0 & \\
\hline Satisfied & 234 & 93.6 & 46 & 18.4 & \\
\hline Very satisfied & 2 & 0.8 & 16 & 6.4 & \\
\hline
\end{tabular}


Table (6): Distribution of the studied women attendance to accredited and non accredited family health units according to their level of satisfaction toward performance of the Nurse.

\begin{tabular}{|c|c|c|c|c|c|}
\hline \multirow{3}{*}{ Item } & \multicolumn{4}{|c|}{ Performance of the nurse } & \multirow{3}{*}{ P. value } \\
\hline & \multicolumn{2}{|c|}{ Accredited } & \multicolumn{2}{|c|}{ Non Accredited } & \\
\hline & No. & $\%$ & No. & $\%$ & \\
\hline \multicolumn{6}{|c|}{ Communication manner of the nurses } \\
\hline Strongly Dissatisfied & 0 & 0.0 & 16 & 6.4 & \multirow{5}{*}{$<0.001 * *$} \\
\hline Dissatisfied & 0 & 0.0 & 55 & 22.0 & \\
\hline To some extent & 23 & 9.2 & 93 & 37.2 & \\
\hline Satisfied & 166 & 66.4 & 71 & 28.4 & \\
\hline Very satisfied & 61 & 24.4 & 15 & 6.0 & \\
\hline \multicolumn{6}{|c|}{ Keeping women privacy by the nurse } \\
\hline Strongly Dissatisfied & 0 & 0.0 & 19 & 7.6 & \multirow{5}{*}{$<0.001 * *$} \\
\hline Dissatisfied & 0 & 0.0 & 64 & 25.6 & \\
\hline To some extent & 65 & 26.0 & 90 & 36.0 & \\
\hline Satisfied & 156 & 62.4 & 60 & 24.0 & \\
\hline Very satisfied & 29 & 11.6 & 17 & 6.8 & \\
\hline \multicolumn{6}{|c|}{ Trusting between women and the nurses } \\
\hline Strongly Dissatisfied & 0 & 0.0 & 15 & 6.0 & \multirow{5}{*}{$<0.001 * *$} \\
\hline Dissatisfied & 2 & 0.8 & 56 & 22.4 & \\
\hline To some extent & 41 & 16.4 & 93 & 37.2 & \\
\hline Satisfied & 100 & 40.0 & 66 & 26.4 & \\
\hline Very satisfied & 107 & 42.8 & 20 & 8.0 & \\
\hline \multicolumn{6}{|c|}{ The nurse Answering women's questions } \\
\hline Strongly Dissatisfied & 0 & 0.0 & 18 & 7.2 & \multirow{5}{*}{$<0.001 * *$} \\
\hline Dissatisfied & 0 & 0.0 & 58 & 23.2 & \\
\hline To some extent & 31 & 12.4 & 93 & 37.2 & \\
\hline Satisfied & 216 & 86.4 & 65 & 26.0 & \\
\hline Very satisfied & 3 & 1.2 & 16 & 6.4 & \\
\hline \multicolumn{6}{|c|}{ The nurse explain the importance of ANC } \\
\hline Strongly Dissatisfied & 0 & 0.0 & 18 & 7.2 & \multirow{5}{*}{$<0.001 * *$} \\
\hline Dissatisfied & 0 & 0.0 & 67 & 26.8 & \\
\hline To some extent & 33 & 13.2 & 83 & 33.2 & \\
\hline Satisfied & 214 & 85.6 & 68 & 27.2 & \\
\hline Very satisfied & 3 & 1.2 & 14 & 5.6 & \\
\hline
\end{tabular}

Table (1): Shows that mean age were about $24 \pm 24$ years in both groups women attendance to accredited and non accredited family health units .Its clear that no statistical significant differences between both groups related to their level of education was observed. All women was recruited in the study were came from rural areas with no statistical significant differences between them were observed

Table (2): Shows that ,there is statistically significant differences in comparison between studied women regards number of dead children, abortion, number of weeks in present pregnancy and number of visits.

Table(3): Shows that significant statistical difference in comparison between studied women regarding to their level of satisfaction about antenatal care in accredited and non accredited family health units was observed.
Table (5): Shows that is statistically significant difference $\mathrm{P}$ value $=<0.001$ between studied women as regards satisfaction of location of the unit, accessibility to the unit, waiting time for $\mathrm{MCH}$ room , Waiting time for out patient clinic and Waiting time for results of laboratory investigations were observed Table (6): Shows that is statistically significant difference $\mathrm{P}$ value $=<0.001$ etween studied women attendance to accredited and non accredited family health units according to their level of satisfaction toward performance of the Nurse (communication manner ,keeping women privacy, trust between women and nurse, answering women questions and explain the importance of antenatal care were observed. 


\section{Discussion}

Worldwide, accreditation has proven to have many benefits. Moreover, patients are the biggest beneficiary with high quality of care and patient safety. It raises community confidence in the services provided by the health care organization and affords the opportunity to the health care unit to benchmark with the best. Additionally, accreditation provides access to reliable and certified information on facilities, infrastructure and level of care. The benefits of accreditation also include providing a framework to help create and implement systems and processes that improve operational effectiveness (National accreditation Board, 2012).

The present study findings presented that the overall women satisfaction with the quality of care services provided to them was relatively high among accredited family health units, while the non accredited family health units presented a minor percentage of satisfaction. This results were supported by other studies which were carried out by (Lamadah, et al., 2012) who assessed women's satisfaction with the quality of care at the primary health centers in KSA, they reported that about two thirds of their studied women were satisfied. Also (Al- azmi et al., 2006) in their study about patient satisfaction with primary health care in Kuwait After Electronic Medical Record they found high level of satisfaction among their studied women.

Regarding observational check list for health care providers, the current study revealed that more than three quarters versus more than one third only of the studied women were reasonably met among to observational checklist full history and menstrual history were fully met among accredited family health units and non-accredited family health units. These results were similar to the results of (Al Eisa, et al., 2005) ,who found that a higher overall patients satisfaction of quality of antenatal care in Riadh health centers. It Seems that the distance between the clients homes and the centers played an important role on the follow up process (Lamadah et al., (2012) however, while poor access to basic ANC is recognized as a major obstacle to improvement in pregnancy outcomes, there is a growing consensus that access to antenatal care alone is insufficient to alter the present maternal healthy profile and that the quality of antenatal services may be a key determinant of maternal and prenatal outcomes (Oladapo et at., 2008 ).

The current study revealed that more than one half of the studied women were satisfied with the accessibility of the units among accredited family health units compared by only one quarter among non accredited family health units. in spite of being from the same catchment area of the unit. This results agreed with the study which were done by Montasser et al., (2012) who assess Egyptian women's satisfaction and perception of ante natal care. They found that near three quarters of the sample were dissatisfied regarding location and accessibility of the unit. At the same line Gemeay (2011) in his study about identification of factors associated with maternal satisfaction with primary health center in Riyadh found that only one tenth were satisfied and about $88 \%$ were not satisfied by accessibility to the hospital. Moreover these results agree with the results of the study conducted in Pakistan that revealed high percent of satisfaction (Anjum, 2005) and it goes in the same line with Lamadah, et al., (2012) who assess women's satisfaction with the quality of care at the primary health centers in KSA they described in their study that most of the sample lived near from the units. Like in other developing country setting where clinic attendance in not based on appointment.

Waiting time remains a big problem Although, it varies from as low as two minutes to as high three hours, it averages over two hours. The current study revealed that women of the accredited family health units were very satisfied toward waiting time at maternal and child health room (MCH ) room and out patient clinic. While one tenth only were satisfied among non accredited family health units.

considered the waiting time to enter the examination room was too long. These variation regarding cleanness are usually related to the characteristics of place of different studies. These results may refer to shortage in medical staff compared to the number of clients or incorrect organizational process of the staff at the two different places of the studies.

Communication by providers with the women during antenatal visits plays an important role ( Douglas et al., 2007), but not the amount of time the provider spends with them, a few minutes spent with the provider appears to have a positive effect on perceived quality (Hansen, et al., 2008 )

The present study about half of the women were satisfied to some extent with examination time in non accredited family health units compared to more than half of women were satisfied among accredited family health units. These findings came in line with the findings of Montasser et al., (2012) about Egyptian women's satisfaction and perception of antenatal care, Daghlia Governorate. Also Hansen et al., (2008) in another two studies conducted in Malawi, presented that poor attitude of health workers have been identified. Another study findings were to the present study by Ghobashi \& Kanderkar, (2008) about satisfaction among expectant mothers with antenatal care in Oman theyfound positive behavior of the health staff. And 
the warm reception mother received in the antenatal care unit were the most satisfying parts of the services . That in agreement of Lamadah et al., (2012) most of health care providers were greeting the clients ,asked clients about the cause of visits , their health problems and they listened carefully to the clients complain .

Regarding privacy as an item of women satisfaction questionnaire the current study showed that about two thirds and more than one tenth were satisfied and very satisfied respectively among accredited family health units but only less than one quarter and few percentage and were satisfied and very satisfied respectively among non accredited family health units .this results can point to the presence of high level of satisfaction in accredited family health units compared to only less than one tenth of the studied women in non accredited family health units. These results were similar to the results of (Montasser et al., (2012) who found that high satisfaction and feeling the privacy among women during their examination .Also Hansen et al .2008) and Oladapo et al .2008) found that ,most of their women were satisfied by the physicians and their nurses as regards maintaining women privacy at the antenatal examination procedures .

Regarding to answering question by the nurse the present study presented that the majority of the women were satisfied among accredited health units versus only about one quarter of the studied women among the non accredited family health units and similar results regarding explanation the importance of antenatal care by the nurse most women were satisfied among accredited and about one quarter only among non accredited family health units. No previous studied conducted before found to compare the item of asking questions.

\section{Conclusion}

The current study concluded that women were more satisfied among accredited family health units than in non accredited family health units.Generally, most of the women were satisfied with the service that they had received in the accredited family health units than non accredited family health units. The present study showed that the criteria of observational checklist for health care providers in accredited family health units were reasonably and fully met more than in non-accredited family health units

\section{Recommendations}

Ministry of health and population should give more attention to primary health care units accreditation program to implemented in all primary health care units.
Women satisfaction surveys should be done routinely in all aspects of reproductive health care to improve the quality of care

\section{References}

1. Abdel Latif (2013): Improving the quality of public hearth Services in Lower income areas , in Cairo , Egypt. The American university in Cairo.

2. Abdel-Razik A., Tawfik A., Hemeda, ElRabbat, Abou-Zeina \& Abdel-Latif (2012): Quality of Primary Health Care Services Within The Framework of The National Accreditation Program . Australian Journal of Basic and Applied Sciences, 6(3): 12-18, 2012 ISSN 1991-8178.

3. Al - Tehewy M., Salem B., Habil I., \& ElOkadai S., (2009): Evaluation of Accreditation Program in Non Governmental Organizations Health Units in Egypt ; Short Terms outcomes. International Journal for quality in Health Care 21, (3) : 183-189.

4. Al-Eisa I., Al-Mutar M., Radwan M., AlTerkit A., (2005): Patients' Satisfaction East. Journal of Family Medicine 2005;3(3). AlMadinah Al-Menawarh, KSA. with Primary Health Care Services at Capital Health Region, Kuwait, Middle Life Science Journal 2012;9(4).4291-4299.

5. Al-Qahtani, M., Al-Dohailan, H., Al-Sharani, \& M., Robinson, (2009): Distributed leadership to mobilise capacity for accreditation research. Journal of Health Organization and Management, 23(2): 255-67.

6. Dhahi. K., Iss A., Hameed A., (2015): A study on pregnant women's satisfaction with primary health care services in Basra. International Journal of Research in Humanities, Arts and Literature (IMPACT: IJRHAL) ISSN(E): 2321 8878; ISSN(P): 2347-4564.

7. Douglas, S., Cervin, C., Bower, K., (2007): What women expect of family physicians as maternity care providers. Can Fam Physician, 53(5), 875-9. International Journal of TROPICAL DISEASE \& Health ,2 (2) : 145$156,2012$.

8. Fikry, Nfabd E-wahed, M., Kassem F., Dyab (2015): Effect of Applying Performance Improvement Model on Ante-Natal Care Nurses Performance in Family Heath Centers in Qena City. Journal of American Science 2015;11(7).169-180.

http://www.jofamericanscience.org.

9. Hansen, P., Peters, D., Viswanathan, K., Rao, K., Mashkoor, A., Burnham, G., (2008): Client perceptions of the quality of primary care 
services in Afghanistan. Int J Qual Health Care, 20(6), 384-391.

10. Lamadah S., Hassan A., Elsaba (2012): Women's Satisfaction with the Quality of Antenatal Care at the Primary Health Care Centers in KSA.

11. Montasser N., Helal R., Megahed W., Amin S., Saad A., Ibrahim T., Abd Elmoneem H., (2012): Egyptian women's satisfaction and perception of antenatal care. International Journal of TROPICAL DISEASE \& Health 2012, 2(2):145-156.

12. Oladapo O., Lyaniwura C., Adewale O., (2008) Quality of antenatal services at the primary care level inSouthwest Nigeria. African Journal ofReproductive Health;12(3):71-92.

13. Pomey, M., Lemieux-Charles, L., Champagne, F., Angus, D., Shabah, A., \& Contandriopoulos, A., (2010): Does accreditation stimulate change? A study of the impact of the accreditation process on Canadian health care organizations. Implementation Science, 5, 31-44.

14. Zenhom S., Saleh N., Amira Elaraby A., (2014): Impact of Accreditation on the information management system in primary health care units in El- Behera governorate, Egypt, Bull- HIPH 2014, 44 (1): 13-20.

15. Bhutta Z., Chopra M., Axelson H., Berman P., Boerma T., Bryce J., (2010): Countdown to 2015 decade report (2000-10): Taking stock of maternal, newborn, and child survival. Lancet 2010;375:2032-44. World

16. Health Orgnization (2010): Trends in Maternal Mortality: 1990-2008, Estimates Developed by WHO, UNICEF, UNFPA, and the World Bank, World Development Indicator database(http.//data world bank. org/data catalog, accessed 1March 2010): World Health Organization; 2010. van Eijk AM, Bles HM, Odhiambo F, Ayisi JG,

17. Blokland I., Rosen D., (2016): Use of antenatal services and delivery care among women in rural western Kenya: A community based survey. ReprodHealth2016;3:2.

18. El-Zanaty F., Way (2011): A. Egypt Demographic and Health Survey 2008. Cairo: Ministry of Health, El Zanaty and Associates and Macro International; 2009, 2011. Available from:

http://www.measuredhs.com/pubs/pdf/FR220/F R220.pdf. [Last accessed on 2011 Nov].

19. GHC (Global Health Council). Report,(2011). Available from: http://www.globalhealth.org/reports/report.php3 . [Last accessed on 2011 Aug].
20. WHO (World Health Organization EMRO Country Profile), (2011): Available from: http://www.emro.who.int/emrinfo/index.asp?Ctr $\mathrm{y}=$ egy. [Last accessed on $2011 \mathrm{Nov}$ ].

21. American Academy of Pediatrics (AAP) \& American College of Obstetricians and Gynecologists (ACOG), (2009): Clinical practice guidelines for preconception and prenatal care. In: Guidelines for Perinatal Care. $6^{\text {th }}$ ed. : AAP; 2009. 